\title{
Autolytic Release of Mannoproteins from Cell Walls of Saccharomyces cerevisiae
}

\author{
By PASCUAL SANZ, ENRIQUE HERRERO AND \\ RAFAEL SENTANDREU* \\ Departament de Microbiología, Facultat de Farmacia, Universitat de València, Avgda Blasco \\ Ibáñez 13, 46010 València, Spain
}

(Received 30 April 1985; revised 16 July 1985)

\begin{abstract}
Autolysis of purified Saccharomyces cerevisiae cell walls resulted in the release of several components thought to be mannoprotein in nature, since they were retained by Concanavalin ASepharose. The most abundant was a $29 \mathrm{kDal}$ molecule which was also a major species among mannoproteins solubilized by the $\beta$-glucanase complex Zymolyase. There was a concomitant release of glucose and mannose oligosaccharides and of $\beta$-glucanase activity. Glucanase and protease inhibitory treatments considerably lowered the release of mannoproteins. The use of different protease inhibitors during autolytic incubations interfered with at least two proteases (one of them being a cysteine protease) apparently involved in the solubilization and partial degradation of mannoproteins from the walls.
\end{abstract}

\section{INTRODUCTION}

Autolysis of yeast cell walls during in vitro incubations is due to hydrolytic enzyme activities present in the organelle (Fleet \& Phaff, 1974; Phaff, 1977; Reichelt \& Fleet, 1981; Notario,

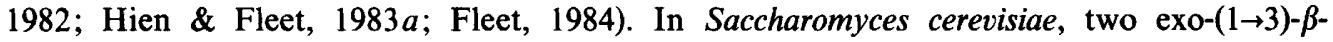
glucanases and four endo-( $1 \rightarrow 3)-\beta$-glucanases have been detected (del Rey et al., 1979; Sánchez et al., 1982; Hien \& Fleet, 1983a), which may act in vivo in wall structuring during vegetative growth and sporulation (del Rey et al., 1979; Hien \& Fleet, 1983b). These glucanases might also be responsible for the degradation of walls during in vitro autolysis. The glucanase molecules themselves are released into the surrounding medium during this process (Hien \& Fleet, 1983a). However, other enzyme activities such as periplasmic chitinase (Elango et al., 1982) or mannanase (Maddox \& Hough, 1971) may also play a role in yeast wall autolysis, as well as hypothetical envelope-associated proteases.

Recently, we have studied the mannoprotein species solubilized by purified Zymolyase (a $\beta$ glucanase complex of bacterial origin; Kitamura et al., 1974) from $S$. cerevisiae walls (Pastor $e t$ al., 1984). Essentially, material of high molecular mass and a $29 \mathrm{kDal}$ mannoprotein were released; these components appeared to interact preferentially with the glucan network of the wall (Shibata et al., 1983; Pastor et al., 1984). Elorza et al. (1985) have extended this study to the mannoproteins released by Zymolyase from Candida albicans walls and found that they have a pattern similar to that of $S$. cerevisiae mannoproteins.

In this paper, we compare the mannoprotein molecules solubilized by Zymolyase with those released by autolysis in $S$. cerevisiae and we investigate the main enzyme activities responsible for their release.

\footnotetext{
Abbreviations: Endo $\mathrm{H}$, endo- $\beta$ - $N$-acetylglucosaminidase $\mathrm{H}$; PHMB, $p$-hydroxymercuribenzoate; PMSF,
} phenylmethylsulphonyl fluoride; TLCK, $N \alpha$-p-tosyl-L-lysine chloromethyl ketone. 


\section{METHODS}

Strain, growth conditions and cell labelling. Saccharomyces cerevisiae X-2180-1A (from the Yeast Genetic Stock Center, University of California, USA) was used. Cells were grown at $28^{\circ} \mathrm{C}$ in yeast nitrogen base medium without amino acids (Difco), supplemented with $2 \%(\mathrm{w} / \mathrm{v})$ glucose. For mannoprotein labelling, $\left[\mathrm{U}-{ }^{14} \mathrm{C}\right]$ protein hydrolysate $\left[0.2 \mu \mathrm{Ci} \mathrm{m}^{-1}\left(7.4 \mathrm{kBq} \mathrm{m}{ }^{-1}\right) ;\right.$ sp. act. $56 \mathrm{mCi}(2072 \mathrm{MBq})$ per mg-atom carbon] was usually added to the cultures at early exponential phase (about $0.2 \mathrm{mg}$ cell dry wt $\mathrm{ml}^{-1}$ ) and incubation continued for $4 \mathrm{~h}$ (up to 0.5 $0.6 \mathrm{mg}$ cell dry $\mathrm{wt} \mathrm{ml}^{-1}$ ). In some experiments the radioactive precursor was added at other growth stages.

Wall autolysis. To isolate and purify walls, cells were washed twice with distilled water, then resuspended in $1 \mathrm{mM}$-phenylmethylsulphonyl fluoride (PMSF) and broken by agitation with glass beads in a Braun homogenizer (five periods of $1 \mathrm{~min}$ ). After sedimenting the walls $(1200 \mathrm{~g}, 10 \mathrm{~min})$, they were washed once with $1 \mathrm{mM}$-PMSF, five times with distilled water and then twice with autolysis buffer ( $50 \mathrm{mM}$-sodium acetate pH 5.5). All the washings were done at $0^{\circ} \mathrm{C}$.

In the standard autolysis procedure, purified walls were resuspended in autolysis buffer $(100 \mu$ l of the latter for walls obtained from $5 \mathrm{mg}$ cell dry wt), plus $5 \mathrm{mM}$-sodium azide, and incubated at $37^{\circ} \mathrm{C}$ in a New Brunswick rotatory shaker at 75 r.p.m. Incubation was continued for $48 \mathrm{~h}$, then walls were sedimented and the released material was recovered from the supernatant by precipitation with 3 vols ethanol $\left(16 \mathrm{~h} \mathrm{at} 4^{\circ} \mathrm{C}\right)$ containing PMSF at $1 \mathrm{mM}$ (final concentration).

Wall treatment with Zymolyase. Zymolyase 5000 was purified by gel filtration and used for solubilization of wall mannoproteins in the presence of $5 \mathrm{mM}$-PMSF, as described by Pastor $e$ t al. (1984).

Mannoprotein analysis. Mannoproteins solubilized either by autolysis or by Zymolyase treatment from radioactively-labelled walls were analysed by SDS-PAGE and fluorography as described previously (Valentin $e t$ al., 1984; Pastor et al., 1984). Concanavalin A-Sepharose 4B binding and digestion by endo- $\beta-N$ acetylglucosaminidase $\mathrm{H}$ (Endo $\mathrm{H}$ ) of the released mannoproteins were as described by Pastor $e t$ al. (1984).

Chromatography of amino acids. Radioactive samples were concentrated to dryness by heating, then resuspended in $6 \mathrm{M}-\mathrm{HCl}$ and treated at $100^{\circ} \mathrm{C}$ for $24 \mathrm{~h}$. The solution was neutralized using Dowex AG $1 \times 8$ (carbonate form), and the supernatant was lyophilized and redissolved in distilled water. The samples were then passed through a Dowex $50 \mathrm{~W} \times 2$ column $(1 \times 5 \mathrm{~cm})$ and, after extensive washing of the latter, amino acids were eluted with $0.5 \mathrm{M}$ ammonia. The eluate was lyophilized, redissolved in $100 \mu \mathrm{l}$ distilled water and then applied to Whatman no. 1 paper. Ascending chromatography (up to $20 \mathrm{~cm}$ ) of duplicate samples was carried out using water-saturated phenol as eluant. One of the chromatograms was cut into $1 \mathrm{~cm}$ pieces and the radioactivity determined in each of these, while the other chromatogram was sprayed with a solution of $0.2 \%(w / v)$ ninhydrin in methanol/acetic acid/water $(50: 1: 49$, by vol.).

Chromatography of sugars. Autolysis supernatants were hydrolysed in $3 \mathrm{M}-\mathrm{HCl}\left(105^{\circ} \mathrm{C}, 4 \mathrm{~h}\right)$. Hydrolysates were neutralized using Dowex AGI $\times 8$ (carbonate form), concentrated by lyophilization and subjected to descending chromatography for $40 \mathrm{~h}$ on Whatman no. 1 paper in ethyl acetate/pyridine/water $(8: 2 ; 1$, by vol.), together with sugar standards.

Enzyme activities. $\beta$-1,3-Glucanase and mannanase activities were determined using laminarin and yeast mannan as respective substrates (Somogyi, 1952), followed by analysis for reducing sugar. Protease activity using Azocoll as substrate was measured as described by Saheki \& Holzer (1974).

Analytical determinations. Total sugar was determined by the phenol/sulphuric acid method using D-glucose as standard (Dubois et al., 1956). Reducing sugar was determined according to Nelson (1944), also with D-glucose as standard.

Chemicals. Dowex AG1 $\times 8$, Dowex $50 \mathrm{~W} \times 2$, dithiothreitol, laminarin, glucono- $\delta$-lactone and all the protease inhibitors were from Sigma. Zymolyase 5000 and Endo $\mathrm{H}$ were from Miles Laboratories. SDS and other electrophoresis reagents were purchased from Bio-Rad. Azocoll was from Hoechst-Behring. [U-14 C]Protein hydrolysate was from Amersham.

\section{RESULTS}

\section{Optimal conditions for autolysis of purified walls}

To quantify the release of mannoproteins during autolysis of $S$. cerevisiae walls, the latter were obtained from cells grown in the presence of a mixture of radioactively-labelled amino acids. Under these conditions, most of the radioactivity incorporated into walls corresponds to the mannoprotein fraction (Valentin et al., 1984).

It has been reported that autolysis of yeast cell walls due to endogenous glucanases occurs at a pH optimum of between 5.0 and 5.5 (Fleet \& Phaff, 1974; Notario, 1982; Hien \& Fleet, 1983a). Thus, all the experiments in this study were done with $S$. cerevisiae walls resuspended in $50 \mathrm{~mm}$ acetate buffer $\mathrm{pH} 5 \cdot 5$. Incubations were done at $37^{\circ} \mathrm{C}$ since we found that at this temperature, as 


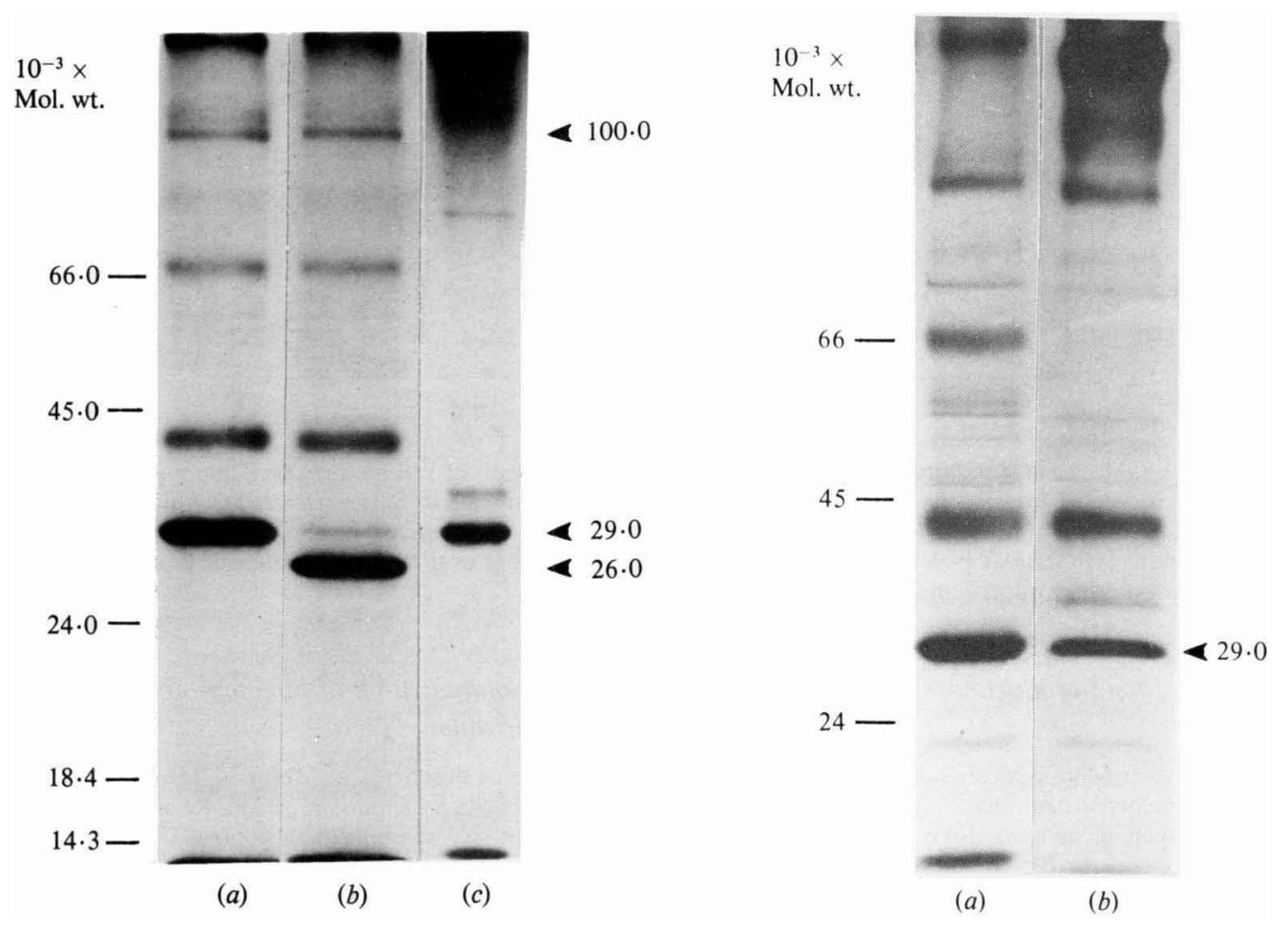

Fig. 1

Fig. 2

Fig. 1. Mannoproteins from radioactively-labelled walls of $S$. cerevisiae X-2180-1A solubilized by autolysis (lane $a$ ) and then treated with Endo $\mathrm{H}$ (lane $b$ ), or by digestion of the walls with purified Zymolyase (lane $c$ ). Released mannoproteins were ethanol-precipitated and analysed by SDS-PAGE and fluorography. Their positions are indicated on the right-hand side.

Fig. 2. Fluorography of mannoproteins from $S$. cerevisiae walls released by autolysis (lane $a$ ) and then retained by Concanavalin A-Sepharose 4B (lane $b$ ). The position of the $29 \mathrm{kDal}$ protein is indicated on the right-hand side.

with $C$. albicans (Elorza et al., 1985), the amount of radioactivity released was double that at $30{ }^{\circ} \mathrm{C}$. Pretreatment of the walls with reducing agents such as dithiothreitol (either before or during incubation in the autolysis buffer) did not improve the level of released radioactivity (data not shown).

To determine if the growth stage of the culture modified the release of wall mannoproteins, radioactive samples taken at the exponential, early and late stationary phases were analysed. Values for radioactivity released from the walls, normalized by the amount of cells (dry weight) in the samples, were independent of the growth stage; in subsequent experiments samples were taken during the late exponential phase.

\section{Individual mannoproteins solubilized during autolysis}

Using the optimal conditions for autolysis, about $20 \%$ of the radioactivity incorporated into walls from $\left[{ }^{14} \mathrm{C}\right]$ protein hydrolysate was solubilized after $48 \mathrm{~h}$. Prolonged incubation did not increase the amount of solubilized radioactivity. Only about $40 \%$ of this radioactivity was ethanol-precipitable and the efficiency of precipitation could not be increased by using acetone or by adding carriers such as yeast mannan or bovine serum albumin.

Material released and precipitated with ethanol was analysed by SDS-PAGE [Fig. 1, lane $(a)$ ]. The most abundant of the released molecules was a $29 \mathrm{kDal}$ mannoprotein with a sugar moiety $\mathrm{N}$-glycosidically-linked to the peptide, since it was sensitive to Endo $\mathrm{H}$ digestion, giving a deglycosylated molecule of $26 \mathrm{kDal}$ [Fig. 1, lane (b)]. This $29 \mathrm{kDal}$ molecule is also preferentially 

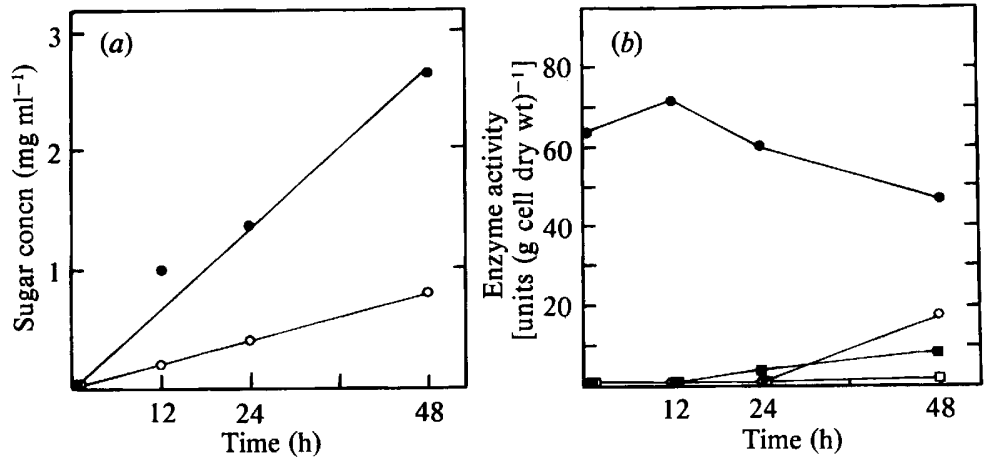

Fig. 3. (a) Release of sugar residues during autolysis of purified walls of $S$. cerevisiae. reducing sugar. (b) Enzyme activities during autolysis of purified walls of $S$. cerevisiae. $\bigcirc, \beta$-Glucanase in the supernatant; $O, \beta$-glucanase in the wall pellet; $\square$, mannanase in the supernatant; $\square$, mannanase in the wall pellet. One unit of enzyme activity is defined as the amount of enzyme that forms $1 \mathrm{nmol}$ product $\min ^{-1}$, under the conditions of the assay.

Table 1. Effect of glucanase and protease inhibitors on the solubilization of mannoproteins during autolysis of $S$. cerevisiae cell walls

Walls were continuously labelled with $\left[{ }^{14} \mathrm{C}\right]$ protein hydrolysate as described in Methods. Inhibitors were incorporated separately into the autolysis buffer for the whole $48 \mathrm{~h}$ incubation period. Results are the mean of at least three independent experiments. Radioactivity solubilized in control samples corresponds to $7060 \mathrm{c} . \mathrm{p} . \mathrm{m}$. for walls obtained from $5 \mathrm{mg}$ (dry wt) of cells.

$\begin{array}{cccr}\begin{array}{c}\text { Radioactivity } \\ \text { solubilized from } \\ \text { walls }\end{array} & \begin{array}{c}\text { Solubilization } \\ \text { relative to } \\ \text { control } \\ (\%)\end{array} & \begin{array}{c}\text { Solubilized radio- } \\ \text { activity ethanol- } \\ \text { precipitable } \\ (\%)\end{array} & \begin{array}{r}\text { Radioact } \\ \text { solubilized } \\ \text { ethanol-precipit } \\ (\%)\end{array} \\ 20 \cdot 0 & 100 \cdot 0 & 41 \cdot 5 & 8 \cdot 3 \\ 13 \cdot 7 & 68 \cdot 5 & 38 \cdot 8 & 5 \cdot 3 \\ 3 \cdot 7 & 18 \cdot 5 & 74 \cdot 0 & 2 \cdot 7 \\ 3 \cdot 5 & 17 \cdot 5 & 38 \cdot 4 & 1 \cdot 3 \\ 5 \cdot 6 & 28 \cdot 0 & 77 \cdot 0 & 4 \cdot 3 \\ 7 \cdot 3 & 36 \cdot 5 & 83 \cdot 8 & 6 \cdot 1 \\ 9 \cdot 0 & 45 \cdot 0 & 63 \cdot 4 & 5 \cdot 7 \\ 7 \cdot 4 & 37 \cdot 0 & 67 \cdot 3 & 5 \cdot 0 \\ 8 \cdot 2 & 41 \cdot 0 & 76 \cdot 4 & 6 \cdot 3 \\ 10 \cdot 3 & 51 \cdot 5 & 43 \cdot 0 & 4 \cdot 4 \\ 12 \cdot 8 & 64 \cdot 0 & 34 \cdot 4 & 4 \cdot 4 \\ 16 \cdot 0 & 80 \cdot 0 & 85 \cdot 5 & 13 \cdot 7 \\ 20 \cdot 7 & 103 \cdot 5 & 31 \cdot 1 & 6 \cdot 5 \\ 26 \cdot 7 & 133 \cdot 5 & 35 \cdot 3 & 9 \cdot 4 \\ 23 \cdot 4 & 117 \cdot 0 & 41 \cdot 7 & 9 \cdot 8 \\ 21 \cdot 0 & 105 \cdot 0 & 54 \cdot 4 & 11 \cdot 4 \\ 20 \cdot 5 & 102 \cdot 5 & 46 \cdot 2 & 9 \cdot 5 \\ 18 \cdot 6 & 93 \cdot 0 & 28 \cdot 4 & 5 \cdot 3\end{array}$

released by Zymolyase digestion of cell walls [Fig. 1, lane (c); Pastor et al. (1984)]. None of the other proteins released by autolysis were Endo $\mathrm{H}$-sensitive. However, most of them were retained by Concanavalin A-Sepharose 4B (Fig. 2), an indication of their glycoprotein nature. Since resistance to Endo $\mathrm{H}$ implies lack of $N$-glycosidically-linked mannose chains, the glycoprotein nature of these molecules must be due to short mannose chains $O$-glycosidicallylinked to the peptide moieties.

$\beta$-Glucanase activities in Zymolyase act on the glucan network of the yeast wall releasing heterogeneous mannoprotein material of high molecular mass (larger than $120 \mathrm{kDal}$ ), in addition to the $29 \mathrm{kDal}$ species (Pastor et al., 1984). About $70 \%$ of these mannoproteins larger than $120 \mathrm{kDal}$ remained in the walls after the $48 \mathrm{~h}$ autolysis period, as determined by digesting 
the pellets of autolysed walls with Zymolyase (data not shown). However, a prominent band of $100 \mathrm{kDal}$ appeared in the supernatant [Fig. 1, lane (a)]. This is about the same size as the $\mathrm{N}$ deglycosylated form of the large heterogeneous material solubilized by Zymolyase (Pastor et al., 1984).

\section{Enzyme activities responsible for wall autolysis}

During the autolytic process a significant amount of carbohydrate was released from the walls (Fig. 3a). Comparison of the levels of total sugar and reducing sugar present in the solution indicates that short saccharide chains are released into the medium. The nature of the liberated residues was determined by paper chromatography after extensive acid hydrolysis. About $60 \%$ of the sugar was glucose, the remainder being mostly mannose, with only a very small amount of $\mathrm{N}$-acetylglucosamine. This is a glucose to mannose ratio similar to that existing in intact walls (Phaff, 1971; unpublished results of the authors). Partially in accordance with the data of Hien \& Fleet $(1983 a)$, the level of glucanase activity in the wall decreased slightly during autolysis, with a corresponding appearance of activity in the supernatant only after $48 \mathrm{~h}$ (Fig. $3 \mathrm{~b}$ ). Some previously cryptic mannanase activity was also measurable in the wall pellet after extensive autolysis, but the level of this enzyme(s) in the supernatant was almost undetectable (Fig. $3 b$ ). Nevertheless, we cannot discount the possibility of this minor mannanase activity being an artifact due to small amounts of glucan contaminating the mannan substrate. The results shown in Fig. 3 were fully reproducible and are of a representative experiment.

Since only about $40 \%$ of the radioactivity previously incorporated into mannoproteins and released into the medium during autolysis was ethanol-precipitable, there was a possibility that the non-precipitable radioactivity was due to small peptides resulting from the action of some protease activity existing in the wall and acting during the autolysis process. To test this, the material that was non-precipitable by ethanol was hydrolysed in strong acid and then chromatographed. Radioactivity appeared in two regions, one of lower mobility mainly corresponding to neutral or basic amino acids and another (containing most of the radioactivity) of higher mobility corresponding to hydrophobic amino acids. Although these data pointed to the existence of wall proteases acting during the autolytic process, we were unable to detect any protease activity either in the wall pellet or in the released material when endogenous wall mannoproteins solubilized by Azocoll or SDS were used as substrates.

\section{Effect of enzyme inhibitors on wall autolysis}

To confirm the role of endogenous glucanases and proteases in wall autolysis and mannoprotein release, the effect of several inhibitors of these activities was tested (Table 1). Glucono- $\delta$-lactone [known to inhibit exo- $\beta$-glucanases and, to a lesser extent, endo- $\beta$-glucanases (Abd-El-Al \& Phaff, 1968; Farkaš et al., 1973)] partially inhibited the autolytic solubilization of radioactivity incorporated into mannoproteins, confirming the role of glucan hydrolysis in the process. Boiling the walls (for $5 \mathrm{~min}$ in autolysis buffer) prior to the $48 \mathrm{~h}$ incubation, a treatment that inactivates glucanases (Notario, 1982; Hien \& Fleet, 1983a) and possibly proteases, also drastically inhibited the release of radioactivity from walls.

$\mathrm{Hg}^{2+}, \mathrm{Zn}^{2+}, p$-hydroxymercuribenzoate (PHMB), iodoacetamide, antipain and chymostatin were the most effective protease inhibitors tested, while a partial effect was also observed with PMSF, $o$-phenanthroline and EDTA. In most cases, a higher inhibitory effect on solubilization of radioactivity correlated with an increased amount of ethanol-precipitated radioactivity; that is, although less radioactivity was released from the walls in the presence of such inhibitors, this preferentially appeared as long peptide chains. As a whole, the amount of radioactivity solubilized and ethanol-precipitated was only slightly diminished by the first group of protease inhibitors (Table 1). Treatment with glucono- $\delta$-lactone plus any of the protease inhibitors effective in reducing the autolytic release of radioactivity resulted in a solubilization level similar to that of the glucanase inhibitor alone (not shown in detail). On the other hand, when PHMB and PMSF were present together, the radioactivity released was less than that released by either of them alone.

The effect of glucanase and protease inhibitors on the autolytic solubilization of individual mannoproteins was studied by SDS-PAGE. Treatments inhibiting glucanase activities 


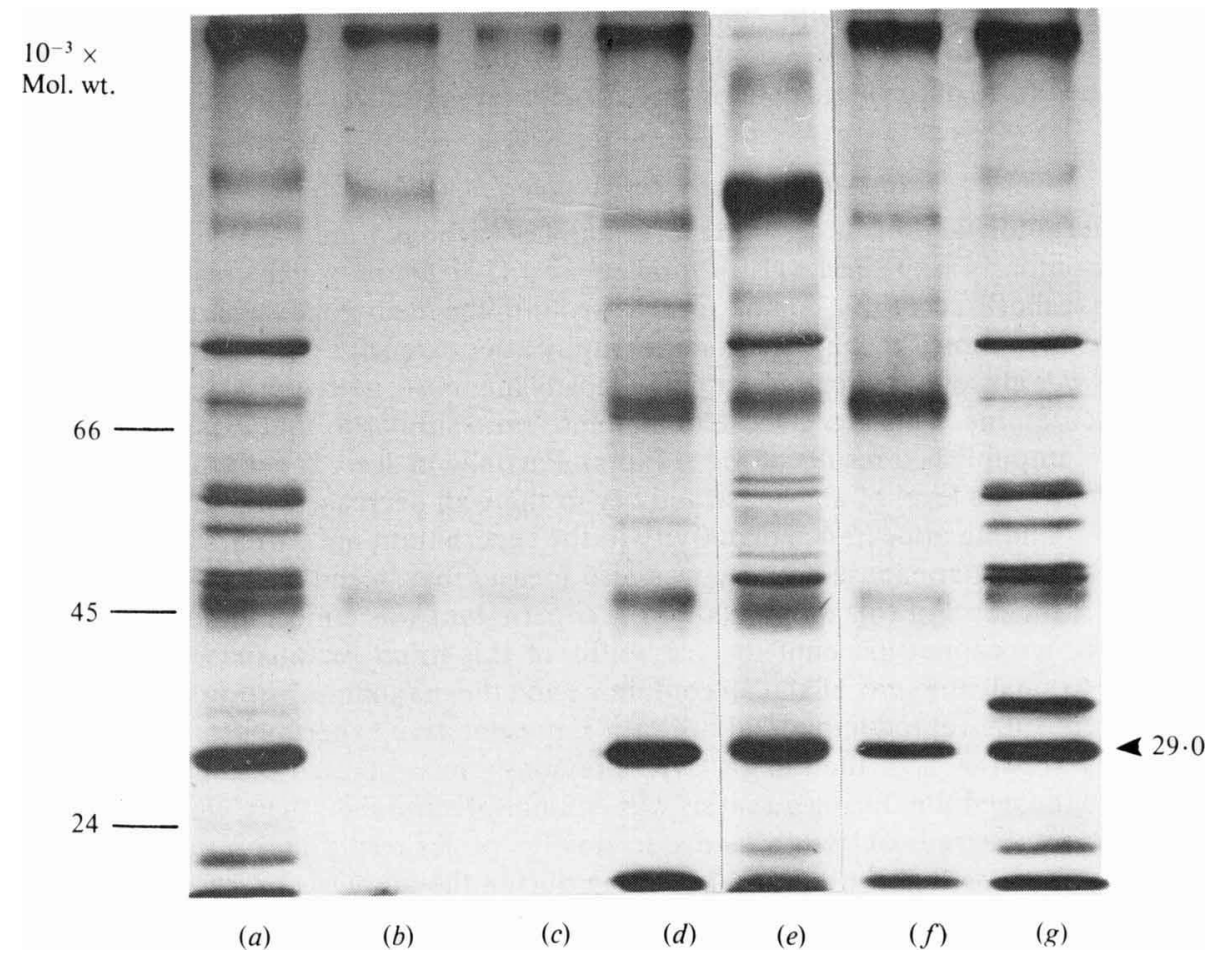

Fig. 4. Fluorography of mannoproteins released by wall autolysis in the presence of glucanase or protease inhibitory treatments. Lanes: $(a)$, control; $(b), 5 \mathrm{~min}$ boiling of the walls: $(c), 300 \mathrm{~mm}$-glucono$\delta$-lactone; $(d), 10 \mathrm{~mm}-\mathrm{Hg}^{2+} ;(e), 5 \mathrm{~mm}-\mathrm{PHMB} ;(f), 5 \mathrm{mM}-\mathrm{PMSF} ;(\mathrm{g}), 5 \mathrm{~mm}-8$-hydroxyquinoline. The position of the $29 \mathrm{kDal}$ protein is indicated on the right-hand side.

negatively affected the release of all the mannoprotein species [Fig. 4, lanes $(b)$ and $(c)$ ], while protease inhibitors such as $\mathrm{Hg}^{2+}$ or PHMB facilitated the release of several molecular species which did not appear in their absence [Fig. 4, lanes $(d)$ and $(e)$ ]. In this case, the $29 \mathrm{kDal}$ mannoprotein was one of the more abundant, together with the $100 \mathrm{kDal}$ species. The $29 \mathrm{kDal}$ mannoprotein was also preferentially solubilized in the presence of PMSF [Fig. 4, lane $(f)]$ or $o$ phenanthroline (not shown). With inhibitors that had no effect on the autolytic solubilization of radioactivity, the released mannoproteins were similar to those of the control [Fig. 4, lane $(g)$, for 8-hydroxyquinoline].

\section{DISCUSSION}

Hydrolysis of the $S$. cerevisiae glucan network by glucanases present in the Zymolyase complex solubilizes several mannoprotein species, mainly heterogeneous material of high molecular mass and a $29 \mathrm{kDal}$ mannoprotein (Pastor et al., 1984). We have proposed that these molecules interact closely with glucan and, in fact, the large material seems to be covalentlylinked to glucan (Shibata et al., 1983; Pastor et al., 1984). Other authors have also shown the role of exogenous $\beta$-glucanases in the release of mannan from yeast cell walls (Bacon et al., 1969; Fleet \& Manners, 1977).

The $29 \mathrm{kDal}$ mannoprotein is also released during the autolytic process, together with other molecules not present in the Zymolyase supernatant. We cannot discount the possibility that at least part of the latter may result from an artifactual alteration of intrinsic wall mannoproteins. The existence of a mannanase activity in the $S$. cerevisiae cell wall has been reported (Maddox \& Hough, 1971). Also, some protease(s) may be present in the wall (see below) and introduce artifacts in the mannoprotein band patterns detected by SDS-PAGE. The material larger than 
$120 \mathrm{kDal}$ (the major component released by Zymolyase digestion) only appears in minor amounts in the supernatant of autolysed walls. However, a $100 \mathrm{kDal}$ band, similar in size to the $\mathrm{N}$-deglycosylated product of the former (Pastor et al., 1984) and no longer Endo $\mathrm{H}$-sensitive was observed in the autolysis supernatant. This $100 \mathrm{kDal}$ molecule was still retained by Concanavalin A-Sepharose 4B, due probably to the presence of $O$-glycosidically-linked oligomannose chains (unpublished results of the authors).

Mannoprotein solubilization under the conditions reported in this paper is concomitant with the release of glucose (as short saccharide chains) to the incubation medium. This confirms the essential role of endogenous glucanases in wall autodegradation [for review, see Fleet (1984)]. Thus, autolytic solubilization of mannoproteins may parallel that caused by Zymolyase and the species released may correspond to those in close interaction with the glucan skeleton. Partial destruction of the latter may alter the whole wall structure, consequently releasing some of the mannoprotein constituents of the wall matrix (Sentandreu et al., 1984). Autolysis of C. albicans cell walls also releases a protein material (Notario, 1982) that is separated by SDS-PAGE into four (blastospores) or two (mycelial cells) bands depending on the cell type (Elorza et al., 1985).

The role of glucan hydrolysis in mannoprotein solubilization was confirmed by the lower amount of mannoprotein released in the presence of glucanase inhibitory treatments (glucono- $\delta$ lactone, boiling of the walls). Although glucono- $\delta$-lactone is a good inhibitor of exo- $\beta$ glucanases, it only partially inhibits endo- $\beta$-glucanases (Abd-El-Al \& Phaff, 1968; Farkaš et al., 1973 ) and this may explain the residual level of mannoprotein release in its presence. Metal ions such as $\mathrm{Hg}^{2+}$ and $\mathrm{Zn}^{2+}$ also inhibit yeast glucanases (Notario et al., 1976; Villa et al., 1978; Notario, 1982). We have shown their interfering effect on the solubilization of wall mannoproteins, but their possible role in the inhibition of some protease must also be considered, at least in the case of $\mathrm{Hg}^{2+}$.

The protease contribution to the autolytic release of radioactivity is shown by the action of several protease inhibitors. Two classes of effects were observed: (i) some of the inhibitors (mercurials, iodoacetamide, antipain, chymostatin) significantly lowered the release of radioactivity while increasing the precipitability by ethanol of the released material, and (ii) other inhibitors (PMSF, o-phenanthroline) affected autolysis to a lesser extent and the precipitability of the solubilized material was the same as in their absence. From these results, it appears that at least two proteases (or protease groups) may be acting during autolysis. One of them would probably be a cysteine protease sensitive to agents interacting with essential thiol groups of the molecule. This protease would hydrolyse previously released peptides to short amino acid chains that were non-precipitable by ethanol. The other protease is less easy to characterize from the nature of the second group of inhibitors, and the existence of more than a single enzyme seems plausible. These proteases would be effective in the release of peptides from the wall structure, without extensively degrading them. Our inability to detect any protease activity in autolysed walls or in the released supernatant might be caused by the lack of accessibility of the substrates used in the assay to the protease molecules of the walls, and/or to the instability of the released enzyme molecules.

Hydrogen and thiol bonds may be important in the interactions between mannoproteins in the wall (Valentin et al., 1984), and covalent linkages between glucan and the large size mannoprotein material seem to exist (Shibata et al., 1983; Pastor et al., 1984). The treatment of yeast cell walls with exogenous proteases causes the release of mannan (Russell et al., 1973). The possibility therefore exists that limited endoproteolysis of some mannoprotein molecules would detach peptide chains from the wall network. In any case, wall proteases would only be effective in solubilizing mannoprotein material after partial autolytic degradation of glucan, as shown by the effect of glucono- $\delta$-lactone and protease inhibitors when present together in the incubation mixture.

To date, only two proteases (aminopeptidases) are thought to be localized outside the yeast cytoplasmic membrane (Frey \& Röhm, 1979; Trumbly \& Bradley, 1983). The relationship between these proteases and those whose existence is suggested from our results remains to be elucidated. 
This work was supported by grants from the Comisión Asesora de Investigación Científica y Técnica. P.S. is the recipient of a predoctoral grant from the Spanish Ministry of Education and Science.

\section{REFERENCES}

Abd-El-Al, A. T. H. \& PhafF, H. J. (1968). Exo- $\beta$ glucanases in yeast. Biochemical Journal 109, 347-360.

BACON, J. S. D., FARMER, V. C., JONES, D. \& TAYLOR, I. F. (1969). The glucan components of the cell wall of baker's yeast (Saccharomyces cerevisiae) considered in relation to its ultrastructure. Biochemical Journal 114, 557-576.

Dubois, M., Gilles, K. A., Hamilton, J. K., Rebers, P. A. \& SMith, F. (1956). Colorimetric method for determination of sugars and related substances. Analytical Chemistry 28, 350-356.

Elango, N., Correa, J. U. \& Cabib, E. (1982). Secretory character of yeast chitinase. Journal of Biological Chemistry 257, 1398-1400.

Elorza, M. V., Murgui, A. \& Sentandreu, R. (1985). Dimorphism in Candida albicans: contribution of mannoproteins to the architecture of yeast and mycelial cell walls. Journal of General Microbiology 131, 2209-2216.

Farkaš, V., Biely, P. \& Bauer, S. (1973). Extracellular $\beta$-glucanases of the yeast Saccharomyces cerevisiae. Biochimica et biophysica acta 21, 246-255.

FLEET, G. H. (1984). The occurrence and function of endogenous wall-degrading enzymes in yeast. In Microbial Cell Wall Synthesis and Autolysis, pp. 227238. Edited by C. Nombela. Amsterdam: Elsevier.

Fleet, G. H. \& Manners, D. J. (1977). The enzymic degradation of an alkali-soluble glucan from the cell walls of Saccharomyces cerevisiae. Journal of General Microbiology 98, 315-327.

Fleet, G. H. \& Phaff, H. J. (1974). Glucanases in Schizosaccharomyces. Isolation and properties of the cell wall associated $(1 \rightarrow 3)-\beta$-glucanases. Journal of Biological Chemistry 249, 1717-1728.

FrEY, J. \& RöHM, K. H. (1979). External and internal forms of yeast aminopeptidase II. European Journal of Biochemistry 97, 169-173.

HiEN, N. H. \& FleET, G. H. (1983a). Separation and characterization of six $(1 \rightarrow 3)$ - $\beta$-glucanases from Saccharomyces cerevisiae. Journal of Bacteriology 156, 1204-1213.

HIEN, N. H. \& FLEET, G. H. (1983b). Variation of $(1 \rightarrow 3)$ - $\beta$-glucanases in Saccharomyces cerevisiae during vegetative growth, conjugation and sporulation. Journal of Bacteriology 156, 1214-1220.

Kitamura, K., Kaneko, T. \& Yamamoto, Y. (1974). Lysis of viable yeast cells by enzymes of Arthrobacter luteus. II. Purification and properties of an enzyme, Zymolyase, which lyses viable yeast cells. Journal of General and Applied Microbiology 20, 323-344.

MadDox, I. S. \& Hough, J. S. (1971). Yeast glucanase and mannanase. Journal of the Institute of Brewing 77 , 44-47.

Nelson, N. (1944). A photometric adaptation of the Somogyi method for the determination of glucose. Journal of Biological Chemistry 153, 375-380.

NotaRIO, V. (1982). $\beta$-Glucanases from Candida albicans: purification, characterization and the nature of their attachment to cell wall components. Journal of General Microbiology 128, 747-759.
Notario, V., Villa, T. G. \& Villanueva, J. R. (1976). Purification of an exo- $\beta$-D-glucanase from cell-free extracts of Candida utilis. Biochemical Journal 159, 555-562.

Pastor, F. I. J., Valentin, E., Herrero, E. \& SENTANDREU, R. (1984). Structure of the Saccharomyces cerevisiae cell wall: mannoproteins released by zymolyase and their contribution to wall architecture. Biochimica et biophysica acta 802, 292-300.

PhafF, H. J. (1971). Structure and biosynthesis of the yeast cell envelope. In The Yeasts, Vol. 2, Physiology and Biochemistry of Yeasts, pp. 135-210. Edited by A. H. Rose \& J. S. Harrison. London: Academic Press.

PhafF, H. J. (1977). Enzymatic yeast cell wall degradation. Advances in Chemistry 160, 244-282.

Reichelt, B. Y. \& FleEt, G. H. (1981). Isolation, properties, function and regulation of endo-( $1 \rightarrow 3)-\beta$ glucanases in Schizosaccharomyces pombe. Journal of Bacteriology 147, 1085-1094.

Rey, F. J. Del, Santos, T., Garcia-Acha, I. \& Nombela, A. C. (1979). Synthesis of 1,3- $\beta$-glucanases in Saccharomyces cerevisiae during the mitotic cycle, mating and sporulation. Journal of Bacteriology 139, 924-931.

Russell, I., Garrison, I. F. \& Stewart, G. G. (1973). Studies on the formation of sphaeroplasts from stationary phase cells of Saccharomyces cerevisiae. Journal of the Institute of Brewing 79, 48-54.

SAHEKI, T. \& Holzer, H. (1974). Comparisons of the tryptophan synthase inactivating enzymes with proteinases from yeast. European Journal of Biochemistry 42, 621-626.

Sanchez, A., Villanueva, J. R. \& Villa, T. G. (1982). Saccharomyces cerevisiae secretes two exo- $\beta$ glucanases. FEBS Letters 138, 209-212.

Sentandreu, R., Herrero, E., Martinez, J. P. \& LARRIBA, G. (1984). Biogenesis of the yeast cell wall. Subcellular Biochemistry 10, 193-235.

Shibata, N., Mizugami, K., Takano, K. \& Suzuki, S. (1983). Isolation of mannan-protein complexes from viable cells of Saccharomyces cerevisiae X2180-1A wild type and Saccharomyces cerevisiae X2180-1A-5 mutant strains by the action of Zymolyase- 60,000 . Journal of Bacteriology 156, 552-558.

SoMOGYI, M. (1952). Notes on sugar determination. Journal of Biological Chemistry 195, 19-23.

Trumbly, R. \& Bradley, G. (1983). Isolation and characterization of aminopeptidase mutants of Saccharomyces cerevisiae. Journal of Bacteriology 156, 36-48.

Valentin, E., Herrero, E., Pastor, F. I. J. \& SENTANDREU, R. (1984). Solubilization and analysis of mannoprotein molecules from the cell wall of Saccharomyces cerevisiae. Journal of General Microbiology 130, 1419-1428.

Villa, T. G., Lachance, M. A. \& PhafF, H. J. (1978). $\beta$-Glucanases of the yeast Kluyveromyces phaseolosporus: partial purification and characterization. Experimental Mycology 2, 12-25. 